\title{
BOVINOCULTURA A PASTO EM LAGUNA CARAPÃ-MS SOB A ÓTICA DA TRANSIÇÃO DO USO DO SOLO
}

\author{
Decline of Pasture-Based Cattle Farming: Land Occupation and Land Use \\ Change in Laguna Carapã, Brazil
}

\section{RESUMO}

Os processos de modernização agropecuária ocorrem em meio a transformações no uso e ocupação do solo. Neste trabalho, objetivou-se descrever as mudanças que ocorreram na produção agropecuária nas últimas décadas em Laguna Carapã-MS, com foco em bovinocultura a pasto. Foram incluídos aspectos de sistema de produção, tecnificação e evolução de índices zootécnicos, socioeconômicos e de desenvolvimento humano. Foram realizadas 5 visitas in loco e adquiridos dados de 22 propriedades rurais, além de acesso a dados públicos do município, do estado e da federação (IBGE-cidades, Sidra: Pesquisa da Pecuária Municipal, SATVeg-Embrapa e MapBiomas). Considerou-se o período de 1985-2017 para uso e ocupação do solo, 1997-2018 para efetivo de rebanho e 2000-2019 para o Índice de Vegetação por Diferença Normalizada (NDVI). As taxas de lotação aumentaram e a pecuária continua predominantemente extensiva. As pastagens podem ser consideradas remanescentes, com diminuição do rebanho efetivo, das vacas ordenhadas e das áreas de pastagem. O cenário configurou a transição da bovinocultura a pasto para a produção de grãos, cereais e energéticos, sendo que a pecuária a pasto não é a renda principal da maioria dos produtores rurais entrevistados. Pastagens destinadas à produção de gado de leite apresentaram menor nível de degradação, uma tendência que pôde diferenciar os produtores de leite, com NDVI médio de 0,58 , dos produtores de gado de corte, com NDVI médio de 0,52 . O estudo revela transições no uso e ocupação do solo e indícios de desenvolvimento municipal que provavelmente retratam tendências em muitos municípios de aptidão agropecuária do centro-oeste do Brasil.

Rodrigo Moraes de Jesus

Universidade Federal da Grande Dourados (UFGD)

rodrigojesu1995@hotmail.com

Marcelo Corrêa da Silva

Universidade Federal da Grande Dourados (UFGD)

marcelo-correadasilva@hotmail.com

Walmes Marques Zeviani

Universidade Federal do Paraná (UFPR)

walmes@ufpr.br

Rodrigo Moura Pereira

EMBRAPA Cerrados

rodrigomouracbs@gmail.com

Carla Eloize Carducci

Universidade Federal da Grande Dourados (UFGD)

carlacarducci@ufgd.edu.br

Recebido em: 17/06/2021. Aprovado em: 25/08/2021.

Avaliado pelo sistema double blind review

Avaliador científico: Caroline Mendonça Nogueira Paiva

DOI: $10.48142 / 2320211789$

\begin{abstract}
Land occupation and land use change receives increasing attention, especially in commodity driven economies. This study aimed to demonstrate some changes that have occurred in agricultural production in recent decades in Laguna Carapã-MS. By focusing on cattle farming in pasture-based systems we describe the technical aspects of the livestock systems and the evolution of zootechnical, socioeconomic and human development indexes overtime. On-site visits were carried out in 22 pasture-based cattle farms. We assessed data from public agencies and government websites (IBGE-cidades, Sidra: Municipal Livestock Research, SATVeg-Embrapa and MapBiomas). The period 1985-2017 was considered for land use and occupation, 1997-2018 for herd numbers and 2000-2019 for the Normalized Difference Vegetation Index (NDVI). The findings showed that stocking rates have increased and that cattle farming remains predominantly extensive. Overtime, there was a remarkable reduction in herd numbers, milked cows and pasture areas declined. Thus, pastures can be considered remnants. The scenario configured a transition from cattle grazing systems to grain, cereal and energy production. Pasture-based cattle farming is not the main income of the majority of cattle farmers interviewed. Pastures used for dairy cattle showed a lower level of degradation, a trend that probably differentiates dairy farmers (average NDVI $\approx 0.58$ ) from beef farmers (average NDVI $\approx 0.52$ ). Overall, the study reveals some of the changes and transitions in land occupation and use and some evidence of municipal development. This probably portray situations and trends in many municipalities in the Midwest of Brazil.
\end{abstract}

Palavras-chave: Commodities Agrícolas; Degradação das Pastagens; Índice de Vegetação com Diferença Normalizada. Keywords: Agricultural commodities; Pasture Degradation; Normalized Difference Vegetation Index. 


\section{INTRODUÇÃO}

As pastagens ocupam, hoje, dois terços da área agricultável no mundo, sendo essa estimada em cinco bilhões de hectares, aproximadamente $38 \%$ da superfície terrestre (FAO, 2020). A baixa fertilidade do solo e o manejo inadequado são apontados como principais causas da degradação das pastagens. Esse é um problema crescente em áreas consideradas produtivas que compromete a rentabilidade da pecuária, com consequências negativas à sustentabilidade do sistema de produção como erosão dos solos, sedimentação de corpos de água, diminuição do valor das terras e o atraso da idade de abate dos animais (Paulino \& Teixeira, 2010; Peron \& Evangelista, 2004; Silva et al., 2017; Reeves \& Baggett, 2014).

Estima-se que o Brasil tenha mais de 120 milhões de hectares de pastagens cultivadas, sendo que $85 \%$ das áreas são forrageiras tropicais do gênero Brachiaria spp. O efetivo nacional é de aproximadamente 173 milhões de cabeças bovinas (IBGE, 2019a; Paulino \& Teixeira, 2010). Ressalta-se que as pastagens degradadas ocorrem em grandes extensões na fronteira agrícola brasileira (Norte, Centro-Oeste e Nordeste), e, aproximadamente 70\% do total apresentam algum grau de degradação (Silva et al., 2017; Dias-Filho, 2014). Mesmo com esses desafios, é possível dizer que a agropecuária é uma das atividades mais importantes no país. No período entre 2010 e 2020, o Brasil se posicionou entre os primeiros lugares no ranking de maior rebanho bovino do mundo (depois da Índia), intercalando a segunda ou terceira posição com a China (USDA, 2021). Estima-se que 2.554.415 estabelecimentos agropecuários criam bovinos de corte no Brasil, o que equivale a 50,3\% do total (IBGE, 2019a). Em 2020, o agronegócio brasileiro (incluindo insumos, indústria, e produção agropecuária), representou aproximadamente $27 \%$ do Produto Interno Bruto (PIB) do país, sendo que a produção agropecuária (setor primário, no campo) representou 7\% do PIB, o que gera milhares de empregos diretos e indiretos (Andrade et al., 2013; CEPEA, 2021).

Com a rápida degradação do solo sob exploração agropecuária nos países em desenvolvimento e de clima tropical, despertou-se nas últimas décadas a preocupação com a sua qualidade e sustentabilidade ambiental (Resende \& Rosolen, 2011). Sendo assim, uma das alternativas tecnológicas que compõem os compromissos voluntários assumidos pelo Brasil na COP-15 visa a restauração de áreas degradadas, e a redução das emissões de gases de efeito estufa (GEEs) até 2030 (Zimmer et al., 2012). Com uma parcela de contribuição destinada à pecuária, inclui-se na ODS 15 (Vida terrestre) que visa: "proteger, recuperar e promover o uso sustentável dos ecossistemas terrestres [...]" (ONU, 2021). Destaca-se a meta 15.3: "Até 2030, combater a desertificação, restaurar a terra e o solo degradado [...]", evidenciando a importância de estudar essa temática (ONU, 2021).

O município de Laguna Carapã, localizado no estado do Mato Grosso do Sul, é de aptidão agropecuária e por esse motivo se mostra como uma unidade passível de retratar as tendências de transformações de uso e ocupação da região, o que o torna interessante como objeto de estudo. Dessa forma, objetivou-se caracterizar o uso e ocupação do solo em Laguna Carapã-MS ao longo das décadas. Mais especificamente, em escala temporal, intencionou-se descrever o modo de exploração adotado na bovinocultura a pasto, incluindo aspectos das pastagens, dos rebanhos, e da tecnificação adotada em sistemas de gado de corte e de leite (a pasto). Propôs-se, também, identificar possíveis mudanças que ocorreram ao longo do tempo na produção agropecuária do município, explorando indicadores de produção zootécnica, dados obtidos por sensoriamento remoto, índices de desenvolvimento humano e desenvolvimento socioeconômico municipal.

\section{AGROPECUÁRIA E USO DO SOLO}

Segundo a FAO (2020), a demanda por alimentos de origem animal a nível mundial aumentará nos próximos anos, devido ao crescimento populacional e o aumento do consumo per capita. As pastagens degradadas impactam diretamente na produtividade de carne, face a demanda alimentar que tem sido um desafio cada vez mais evidente e crescente. As mudanças no uso da terra e intensificação da agricultura podem aumentar o risco de degradação física, química e biológica do solo, o que diminui sua fertilidade com impactos negativos na produtividade agrícola. No caso da atividade agropecuária, as circunstâncias econômicas podem levar a uma intensificação da produção que tende a aumentar os excedentes de resíduos que inevitavelmente levam a perdas ambientais e impactos relacionados ao solo e à água (Bittman et al., 2011). Cunha et al. (2008) reforçam a importância do setor agropecuário na solução dos problemas de degradação ambiental, em que a responsabilidade de assegurar uma agricultura sustentável recai em grande parte sobre as empresas agrícolas, em especial nos partícipes diretos do desenvolvimento da agropecuária. Os solos ocupados por pastagens, em geral, são marginais quando comparados àqueles usados pela agricultura de grãos. Esses apresentam problemas de fertilidade natural, acidez, topografia, pedregosidade ou limitações de drenagem. Dessa 
forma, é de se esperar que as áreas de exploração dos bovinos de corte apresentem problemas de produtividade e de sustentabilidade de produção (Macedo et al., 2000).

Dada a necessidade de intervenção nos processos de degradação, técnicas de recuperação menos onerosas estão surgindo e uma delas é a recuperação de áreas degradadas por pastagem (Salomão et al., 2020). Em uma pastagem degradada, a produção animal pode ser seis vezes menor do que numa pastagem em boas condições ou recuperada (Macedo et al., 2000). Estima-se que $80 \%$ dos 50 a 60 milhões de hectares das cultivadas no Brasil Central encontram-se em algum estado de degradação. Elas estão em processo evolutivo de perda de vigor, sem possibilidade de recuperação natural e incapazes de sustentar os níveis de produção e qualidade exigida pelos animais, bem como de superar os efeitos nocivos de pragas, doenças e plantas invasoras (Carvalho et al., 2017).

De acordo com Soares Filho et al. (1992), uma pastagem está em processo de degradação quando a produção de forragem diminui a sua qualidade e quantidade. Mesmo nas épocas favoráveis ao seu crescimento, há o aparecimento de espécies invasoras competindo por nutrientes e de processos erosivos causados pela ação das chuvas. Desse modo, a degradação de pastagens gera grandes prejuízos econômicos e ambientais. Entender esse processo e saber como evitá-lo é essencial para aumentar a produtividade no campo e diminuir o desmatamento (Carvalho et al., 2017). Compreender como essa problemática é definida tem vital importância no sentido de se apropriar do tema e, assim, ser capaz de perceber as variáveis que a envolve. Dessa forma, torna-se mais eficiente a discussão desse tema no contexto atual do agronegócio brasileiro, o qual é de extrema relevância visto o papel que o país tem na produção mundial de bovinos para a geração de carne e leite, juntamente da necessidade de preservar e conservar o meio ambiente.

Com o processo de tecnificação das áreas agrícolas e de modernização na expansão das áreas cultivadas, observa-se algumas tendências, como a transição gradativa das áreas sob pastagem em cultivos agrícolas. Em Mato Grosso, por exemplo, a conversão de pastagens em lavouras representou cerca de $49 \%$ da expansão entre os anos de 2000 e 2013 (Cohn et al., 2016), com destaque para a produção de grãos, cereais e energéticos. Nesse mesmo período, em Mato Grosso do Sul, segundo o Projeto MapBiomas (2019), a conversão de pastagens em lavoura e sua expansão foi de cerca de 52\%. Para facilitar a análise e a gestão dessas áreas de pastagem, é necessária a utilização de ferramentas de fácil acesso que promovam o seu monitoramento. Por isso, as técnicas de sensoriamento remoto tornam-se de grande valia para a avaliação de qualidade das pastagens, sendo o índice de vegetação por diferença normalizada (NDVI) uma ótima ferramenta para esse propósito (Valle Júnior et al., 2019). Entender o processo de transformação do uso e ocupação do solo em relação às pastagens remanescentes é importante para revelar tendências na produção agropecuária, incluindo as práticas de manejo e gestão adotadas nesse procedimento (Barcellos et al., 2008).

\section{SENSORIAMENTO REMOTO E O MONITORAMENTO DAS PASTAGENS}

As técnicas de sensoriamento remoto e geoprocessamento são bastante promissoras para a identificação e classificação dos estágios em que as pastagens se encontram. Assim, é possível propor metodologias que possam avaliá-las e classificá-las. Dessa maneira, o sensoriamento remoto é um instrumento atraente para avaliar e diagnosticar rapidamente a prevalência e o status da degradação (Zhumanova et al., 2018). Os produtos obtidos por sensoriamento remoto têm sido uma importante ferramenta no fornecimento de informações pertinentes à avaliação das condições da vegetação, devido a sua alta disponibilidade de dados sinóticos, abrangência espacial, baixo custo relativo e disponibilidade de dados quase em tempo real (Liu, 2006).

O uso do sensoriamento remoto de imagens orbitais associado a técnicas de geoprocessamento por meio dos Sistemas de Informações Geográficas tem sido aplicado na detecção de mudanças no uso e cobertura da terra, bem como nas alterações provocadas em paisagens de um determinado local e escala temporal, além do uso do monitoramento orbital, o que possibilita o diagnóstico de alterações antrópicas e naturais na paisagem (Cunha et al., 2012). Nas aplicações de sensoriamento remoto, os índices de vegetação são utilizados para monitorar e quantificar as condições e distribuições espaciais das vegetações a partir da aplicação de operações matemáticas em dados de reflectância espectral da radiação eletromagnética, em imagens obtidas por sensores a bordo de diversos satélites (Liu, 2006).

Os índices de vegetação permitem avaliar os diferentes usos e coberturas do solo, além de discriminar diferentes sistemas de uso dentro da mesma classe de cobertura vegetal. Fonseca et al., (2018) utilizaram o Índice de Vegetação por Diferença Normalizada (NDVI) a partir do satélite OLI/Landsat 8 para detectar os processos de degradação de pastagens cultivadas no município de Colorado do Oeste - RO. Nesse caso, foi possível observar que $67 \%$ do município apresentou algum grau de degradação das pastagens. Conceição et al. (2021) avaliaram o 
efeito de sistemas pecuários relacionando-os ao NDVI, e verificou-se que os maiores valores de NDVI ocorreram em sistema de integração lavoura-pecuária-florestam, sendo possível discriminar a partir dos dados os sistemas mais produtivos e menos produtivos, principalmente nos períodos de seca.

\section{METODOLOGIA}

\subsection{Descrição da área de estudo}

$\mathrm{O}$ estudo foi desenvolvido em áreas de pastagens de gado no município de Laguna Carapã-MS (Figura 1), situado na região sul fronteira do estado de Mato Grosso do Sul. O local possui uma área de $1.734 \mathrm{~km}^{2}$, população estimada em 7.341 habitantes, e é localizada a $239 \mathrm{~km}$ da capital Campo Grande, sob as coordenadas $22^{\circ} 32$ ' 32" S, $55^{\circ}$ 9' 25 'O. O município dispõe de 424 estabelecimentos agropecuários (unidades de produção ou exploração), 346 de produtores individuais dos quais 340 possuem lavouras temporárias, 168 pastagens naturais, 122 pastagens plantadas e 251 destinadas a bovinos de corte ou leite (IBGE, 2019a; IGBE, 2019c). As precipitações variam de $1.500 \mathrm{~mm}$ a $1.700 \mathrm{~mm}$ anuais, e o solo predominante no município é o Latossolo Vermelho distroférrico (SEMADE, 2011).

\subsection{Coleta de dados primários}

Foram realizadas visitas a campo in loco em 5 propriedades que praticam a produção de gado de corte ou de leite a pasto, também foram obtidas fotografias digitais do aspecto visual das pastagens. Essas propriedades fazem parte das 22 analisadas com NDVI (Tabelas 1 e 2), as quais foram escolhidas devido às suas características distintas e à sua disponibilidade de acesso a propriedade e informações. Durante as visitas, conversas foram realizadas junto aos pecuaristas para explorar e compreender como era realizado o manejo das áreas sob pastagens. Simultaneamente, realizaram-se visitações à órgãos públicos municipais, estaduais e organizações da sociedade civil como o Sindicato Rural, a Prefeitura, a Agência de Desenvolvimento Agrário e Extensão Rural (Agraer) e a Agência Estadual de Defesa Sanitária Animal e Vegetal (Iagro). Nessas situações, foram levantados dados sobre: tamanho da área de pastagens da propriedade; gênero de gramíneas; raças bovinas; número de animais por propriedade; tecnificação empregada na produção (insumos agrícolas, manejo, ração animal, feno, silagem, suplementação, presença de outra cultura agrícola na propriedade); e se o produtor tinha na pecuária sua principal atividade ou não. Todas essas informações foram analisadas em conjunto para a geração dos resultados.
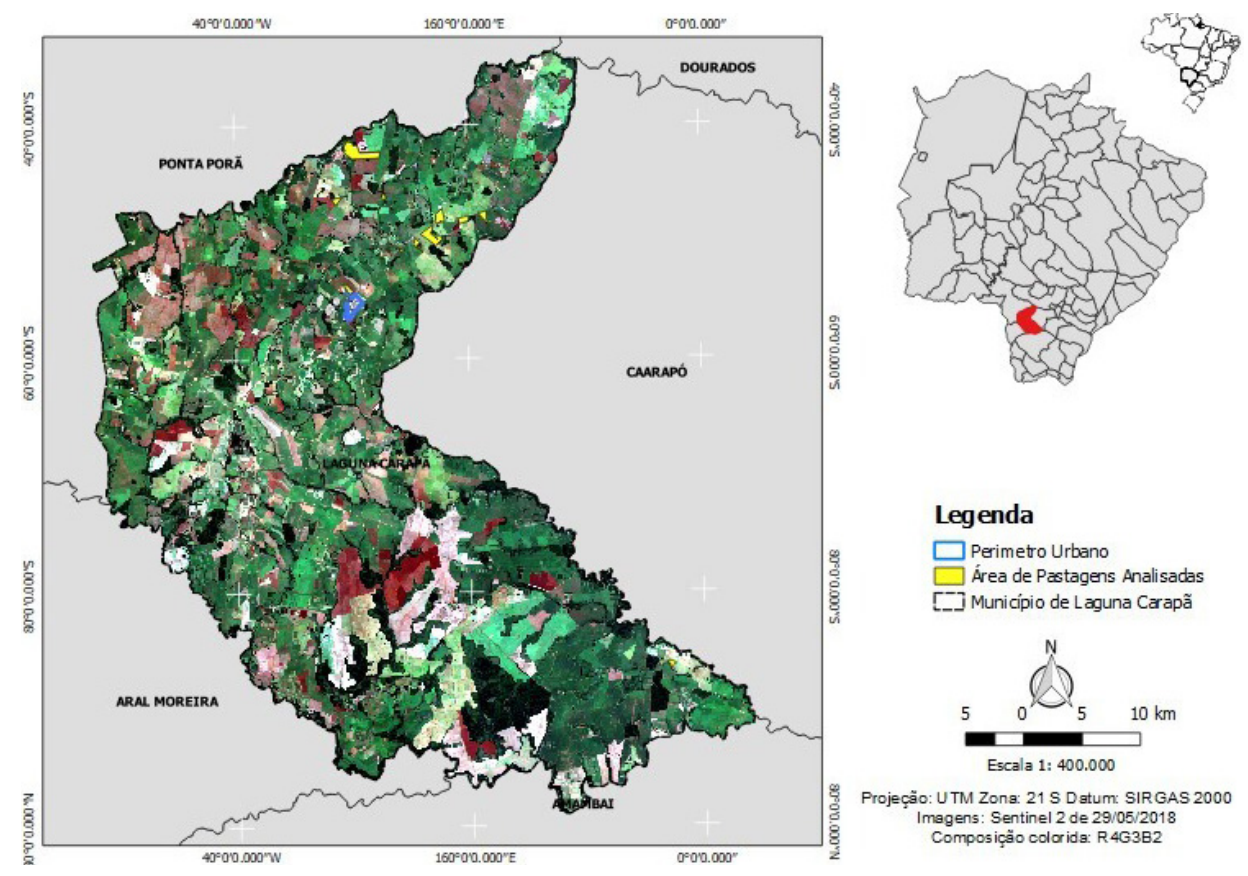

\section{Legenda}

$\square$ Perimetro Urbano

$\square$ Área de Pastagens Analisadas $[-]$ Município de Laguna Carapã

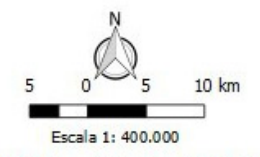

Projeçăo: U TM Zona: 21 S Datum: SIR GAS 2000 Imagens: Sentinel 2 de 29/05/2018
Composiçäo colorida: R 4G3B2

FIGURA 1 - Localização do Município de Laguna Carapã, MS, Brasil e propriedades de pastagens analisadas Fonte: Elaborada pelos autores (2021)

Organizações Rurais \& Agroindustriais, Lavras, v. 23, e1789, 2021 
TABELA 1 - Localização das propriedades rurais (área de pastagens*) no município de Laguna Carapã.

\begin{tabular}{|c|c|c|c|c|c|c|c|c|c|}
\hline \multirow{2}{*}{$\frac{\text { Amostra }}{\mathrm{A}}$} & \multicolumn{2}{|c|}{ Coordenadas UTM } & \multirow{2}{*}{$\begin{array}{c}\text { Produto } \\
\text { Corte }\end{array}$} & \multirow{2}{*}{$\frac{\text { Raça }}{\text { NEL }}$} & \multirow{2}{*}{$\frac{\text { Manejo }}{E}$} & \multirow{2}{*}{$\begin{array}{c}\text { Renda principal/ } \\
\text { gado }\end{array}$} & \multirow{2}{*}{$\frac{\text { Quantidade }}{850}$} & \multirow{2}{*}{$\frac{\text { Área (ha) }}{500}$} & \multirow{2}{*}{$\begin{array}{c}\text { Taxa de lotação } \\
(\text { animal ha-1) }\end{array}$} \\
\hline & -5510938 & -2251146 & & & & & & & \\
\hline $\mathrm{Ab}$ & -5515729 & -2246979 & Corte & NEL & E & Não & 175 & 70 & 2.50 \\
\hline B & -5516563 & -2245938 & Corte & NEL e ANG & $\mathrm{S}$ & Não & 900 & 350 & 2.57 \\
\hline $\mathrm{C}$ & -5515313 & -2254688 & Leite & GRL e HOL & S & Não & 35 & 11 & 3.18 \\
\hline $\mathrm{Cd}$ & -5511354 & -2251146 & Leite & JER & $\mathrm{E}$ & Sim & 27 & 7 & 3.85 \\
\hline $\mathrm{F}$ & -5504063 & -2248854 & Corte & NEL & $\mathrm{S}$ & Não & 47 & 35 & 1.34 \\
\hline Gh & -5512396 & -2250104 & Leite & HOL & $\mathrm{S}$ & Não & 6 & 2.7 & 2.22 \\
\hline I & -5506979 & -2248646 & $\begin{array}{l}\text { Corte e } \\
\text { Leite }\end{array}$ & $\begin{array}{c}\text { NEL, ANG e } \\
\text { HOL }\end{array}$ & $\mathrm{S}$ & Sim & 400 & 303 & 1.32 \\
\hline $\mathrm{Ij}$ & -5510938 & -2250938 & Leite & GIR e HOL & $\mathrm{E}$ & Não & 35 & 9 & 3.88 \\
\hline $\mathrm{K}$ & -5509479 & -2250313 & Corte & GIR e NEL & $\mathrm{E}$ & Não & 1050 & 750 & 1.40 \\
\hline $\mathrm{N}$ & -5506146 & -2248854 & Corte & NEL & $\mathrm{S}$ & Sim & 450 & 200 & 2.25 \\
\hline $\mathrm{O}$ & -5510104 & -2247813 & Leite & GRL & $\mathrm{S}$ & Sim & 40 & 26 & 1.53 \\
\hline $\mathrm{P}$ & -5511979 & -2250729 & Corte & NEL & $\mathrm{E}$ & Não & 15 & 8 & 1.87 \\
\hline Q & -5512188 & -2251979 & Corte & NEL e ANG & $\mathrm{E}$ & Não & 65 & 25 & 2.60 \\
\hline $\mathrm{R}$ & -5510313 & -2248854 & Leite & HOL & $\mathrm{E}$ & Não & 5 & 1 & 5.00 \\
\hline $\mathrm{S}$ & -5510521 & -2247813 & Corte & NEL & $\mathrm{E}$ & Não & 35 & 25 & 1.40 \\
\hline $\mathrm{T}$ & -5510313 & -2249063 & Leite & GRL & $\mathrm{E}$ & Não & 30 & 30 & 1.00 \\
\hline $\mathrm{V}$ & -5508646 & -2269479 & Leite & GRL & $\mathrm{S}$ & Sim & 10 & 18 & 0.55 \\
\hline W & -5511563 & -2250938 & Leite & GIR e HOL & $\mathrm{E}$ & Não & 11 & 2.5 & 4.40 \\
\hline $\mathrm{X}$ & -5511979 & -2250104 & Leite & GRL e HOL & I & Sim & 59 & 7 & 8.42 \\
\hline Y & -5511979 & -2251563 & Leite & GRL & $\mathrm{E}$ & Não & 3 & 0.5 & 1.50 \\
\hline $\mathrm{Z}$ & -5510521 & -2246146 & Leite & HOL & $\mathrm{E}$ & Não & 5 & 1.5 & 3.33 \\
\hline
\end{tabular}

Nota. Dados primários das propriedades rurais de produtores de bovinos de leite e corte, coletados in loco e compilados a partir de dados de órgãos municipais: Prefeitura municipal, Sindicato rural e entrevista. Ano: 2019. Siglas: NEL - Nelore; ANG - Angus; GRL - Girolanda; HOL - Holandesa; JER - Jersolanda; GIR - Gir; E - extensivo; S - semi-intensivo; I - intensivo. *Todas as propriedades analisadas possuem as pastagens do tipo Brachiaria sp.

Fonte: Elaborada pelos autores (2021).

A partir dos dados obtidos pelos órgãos públicos, na questão de manejo e tecnificação, as propriedades foram então classificadas segundo os parâmetros por eles definidos. Sendo assim, considerado um sistema extensivo quando presente apenas gado a pasto; semi -intensivo quando possuía algum tipo de tecnificação, mas não para uma alta performance; e intensivo quando o produtor possuía um sistema de gestão e manejo visando alta performance, com tecnologias focadas na maior produtividade na bovinocultura. Foi utilizada a técnica visual de avaliação de qualidade de pastagens, que classifica as pastagens em quatro níveis de degradação, de acordo com o método proposto por Dias-Filho (2017). Essa técnica é baseada nas variações de degradação das pastagens, sendo estas:
Nível 1, (Leve): Pastagem ainda produtiva, apresentando algumas áreas de solo descoberto ou plantas daninhas. A capacidade de suporte diminui cerca de $20 \%$ em relação a pastagem não degradada;

Nível 2, (Moderado): Aumento na infestação de plantas daninhas ou no percentual de solo descoberto. A capacidade de suporte diminui entre $30 \%$ e $50 \%$;

Nível 3, (Forte): Aumento excessivo da infestação de plantas daninhas ou no percentual de solo descoberto em relação ao nível 2, com baixa proporção de pastagens. A capacidade de suporte diminui entre $60 \%$ e $80 \%$;

Nível 4 (Muito Forte): Predomínio de solo descoberto, com sinais evidentes de erosão, com proporção de pastagens muito baixa ou inexistente. A capacidade de suporte diminui acima de 80\% (Dias-Filho, 2017). 
TABELA 2 - Análise descritiva dos dados de NDVI globais, obtidos para áreas de pastagens de 22 propriedades rurais do município de Laguna Carapã-MS.

\begin{tabular}{cccccccc}
\hline Propriedades & Atividade & Média & DP & CV $(\%)$ & Mediana & Mínimo & Máximo \\
\hline $\mathrm{A}$ & Corte & 0,6 & 0,14 & 22,71 & 0,61 & $-0,30$ & 0,87 \\
$\mathrm{Ab}$ & Corte & 0,54 & 0,13 & 24,61 & 0,55 & 0,11 & 0,89 \\
$\mathrm{~B}$ & Corte & 0,56 & 0,13 & 23,79 & 0,57 & $-0,30$ & 0,89 \\
$\mathrm{~F}$ & Corte & 0,52 & 0,21 & 39,26 & 0,51 & $-0,30$ & 0,93 \\
$\mathrm{~K}$ & Corte & 0,52 & 0,12 & 22,81 & 0,53 & $-0,30$ & 0,78 \\
$\mathrm{~N}$ & Corte & 0,54 & 0,14 & 26,51 & 0,55 & $-0,30$ & 0,83 \\
$\mathrm{P}$ & Corte & 0,61 & 0,13 & 20,89 & 0,63 & $-0,30$ & 0,85 \\
$\mathrm{Q}$ & Corte & 0,55 & 0,18 & 31,91 & 0,55 & $-0,30$ & 0,90 \\
$\mathrm{~S}$ & Corte & 0,52 & 0,15 & 28,34 & 0,52 & $-0,30$ & 0,85 \\
$\mathrm{C}$ & Leite & 0,53 & 0,12 & 23,06 & 0,53 & 0,19 & 0,85 \\
$\mathrm{Cd}$ & Leite & 0,59 & 0,13 & 21,50 & 0,61 & 0,09 & 0,85 \\
$\mathrm{Gh}$ & Leite & 0,6 & 0,14 & 22,67 & 0,60 & 0,14 & 0,89 \\
$\mathrm{Ij}$ & Leite & 0,58 & 0,13 & 21,75 & 0,58 & 0,15 & 0,94 \\
$\mathrm{O}$ & Leite & 0,54 & 0,12 & 22,92 & 0,55 & $-0,30$ & 0,84 \\
$\mathrm{R}$ & Leite & 0,56 & 0,18 & 31,34 & 0,56 & $-0,30$ & 0,92 \\
$\mathrm{~T}$ & Leite & 0,6 & 0,16 & 27,20 & 0,62 & $-0,30$ & 0,90 \\
$\mathrm{~V}$ & Leite & 0,53 & 0,15 & 27,78 & 0,55 & $-0,30$ & 0,85 \\
$\mathrm{~W}$ & Leite & 0,59 & 0,15 & 26,14 & 0,59 & 0,16 & 0,92 \\
$\mathrm{X}$ & Leite & 0,66 & 0,11 & 16,80 & 0,68 & 0,10 & 0,88 \\
$\mathrm{Y}$ & Leite & 0,56 & 0,15 & 26,50 & 0,56 & 0,24 & 0,91 \\
$\mathrm{Z}$ & Leite & 0,58 & 0,18 & 30,30 & 0,60 & 0,19 & 0,95 \\
$\mathrm{I}$ & Corte e Leite & 0,56 & 0,14 & 25,02 & 0,58 & $-0,30$ & 0,85 \\
\hline
\end{tabular}

Nota. Análise descritiva dos dados de NDVI globais, obtidos para áreas de pastagens de 22 propriedades rurais do município de Laguna Carapã-MS. Separado por atividades: corte, leite e ambos (Corte e leite). Siglas: CV - coeficiente de variação; DP - desvio padrão Fonte: Elaborada pelos autores (2021)

\subsection{Coleta de dados secundários}

Foram coletadas informações em bancos de dados públicos, sendo uma delas a série histórica de uso e ocupação do município de Laguna Carapã entre 1985 e 2017, do Projeto MapBiomas (2019). Com base nessa série, obtevese as seguintes informações: áreas de pastagens, florestas, cultivo anual e perene, e cultivo semi-perene. Foram também utilizados dados disponíveis no IBGE Cidades e Atlas de Desenvolvimento Humano no Brasil, através dos quais foram coletados dados sobre renda, educação, saúde, escolaridades e índices como Produto Interno Bruto (PIB) e o Índice de Desenvolvimento Humano (IDH), em relação aos demais municípios brasileiros. Ainda, no sistema SIDRA (IBGE), adquiriu-se dados de séries históricas da pecuária municipal, sobre efetivo de rebanho e vacas ordenhadas do período entre 1997 e 2018 (IBGE, 2019b).

\subsection{NDVI, análise descritiva e séries históricas}

O Índice de Vegetação por Diferença Normalizada (NDVI) é uma medida quantitativa baseada nas propriedades espectrais da vegetação e na biomassa verde em vigor (Persson et al., 2018; Tomasella et al., 2018). O NDVI tem sido utilizado como indicador de monitoramento da degradação das pastagens e das mudanças de uso do solo (Karimi et al., 2016) e é definido pela seguinte equação (Equação 1):

$\mathrm{NDVI}=(\mathrm{IVP}-\mathrm{V}) /(\mathrm{IVP}+\mathrm{V})$

em que IVP = reflectância no infravermelho próximo; e V $=$ reflectância no vermelho.

Essa variação é expressa por meio de uma escala numérica de $-1,0$ (ausência de vegetação) a 1,0 (maior

Organizações Rurais \& Agroindustriais, Lavras, v. 23, e1789, 2021 
índice de vegetação). Ou seja, quanto maior o valor positivo do NDVI, maior a presença de vegetação fotossitenticamente ativa (Guilherme et al., 2016).

Para realização da análise de NDVI, foi utilizado o sistema SATVeg, (Sistema de Análise Temporal da Vegetação), uma ferramenta Web desenvolvida pela Embrapa Informática Agropecuária. Este instrumento é destinado ao acesso de perfis temporais dos índices vegetativos NDVI e EVI do sensor MODIS. A abrangência inclui qualquer local da América do Sul (EMBRAPA, 2019). A partir desse sistema, foram coletadas a série histórica de NDVI do município de Laguna Carapã em 22 propriedades rurais, por meio das coordenadas geográficas e seleção das áreas (polígonos) de pastagens (Figura 1). No sistema SATVEg, foram utilizados dados de NDVI de fevereiro de 2000 até 2019, sendo as imagens de satélite capturadas a cada 16 dias. As propriedades rurais foram selecionadas de acordo com a disponibilidade de dados, concedidos por órgãos públicos ou produtores rurais.

Com a obtenção da média global de NDVI, em cada propriedade, calcularam-se os seguintes dados: média, desvio padrão, mediana, máximo e mínimo. Além da análise de variância (ANOVA), estimativas de correlação de Pearson e teste de Tukey para comparação das médias. Ao utilizar as ferramentas estatísticas pretendeu-se detectar diferenças nas pastagens utilizadas para produção de carne e leite. Ainda, foram realizadas manobras analíticas de síntese (splines) das séries históricas de NDVI, com o uso do pacote lattice, lattice Extra, splines e mgcv no software R (R Core Team, 2020).

\section{RESULTADOS E DISCUSSÃO}

\subsection{Uso e ocupação do solo}

Com os dados do Projeto MapBiomas (2019), foi possível observar a série histórica de uso do solo entre 1985 e 2017. Nesse período, houve transição substancial das áreas ocupadas por pastagens naturais e plantadas para a agricultura anual e perene (Figura 2). Verificou-se que em 1985, áreas de pastagem ocupavam 72.804 ha, contra 19.383 ha de áreas destinadas a culturas anuais e perenes. Em 2002, a área destinada a estes tipos de uso do solo foi similar devido à redução das áreas de pastagens e ao aumento de culturas anuais e perenes (aproximadamente 56.539 ha de pastagens contra 51.780 ha de culturas anuais e perenes). Já em 2017, as áreas destinadas a pastagens eram de 11.678 ha, contra 95.894 ha destinadas a culturas anuais e perenes. As culturas semi-perenes foram identificadas no município a partir de 2009, a exemplo do cultivo de cana-de-açúcar, devido à instalação de usinas de produção de açúcar e etanol na região (Faccini \& Merêncio, 2019).

Foi possível observar que as áreas de florestas permaneceram constantes no período analisado, com pequeno incremento em ocupação referente a $1 \%$, embora não tenham sido realizadas avaliações de qualidade nesses fragmentos florestais, o que seria oportuno para complementar e qualificar esses processos de transformação da paisagem (Young et al., 2020). Já as florestas plantadas foram evidentes a partir de 2007 , mesmo com baixo valor quando comparadas às outras atividades desenvolvidas no município. Porém, isso pode indicar iniciativas de recuperação de áreas degradadas ou de atividades de silvicultura com plantações de eucaliptos na região.

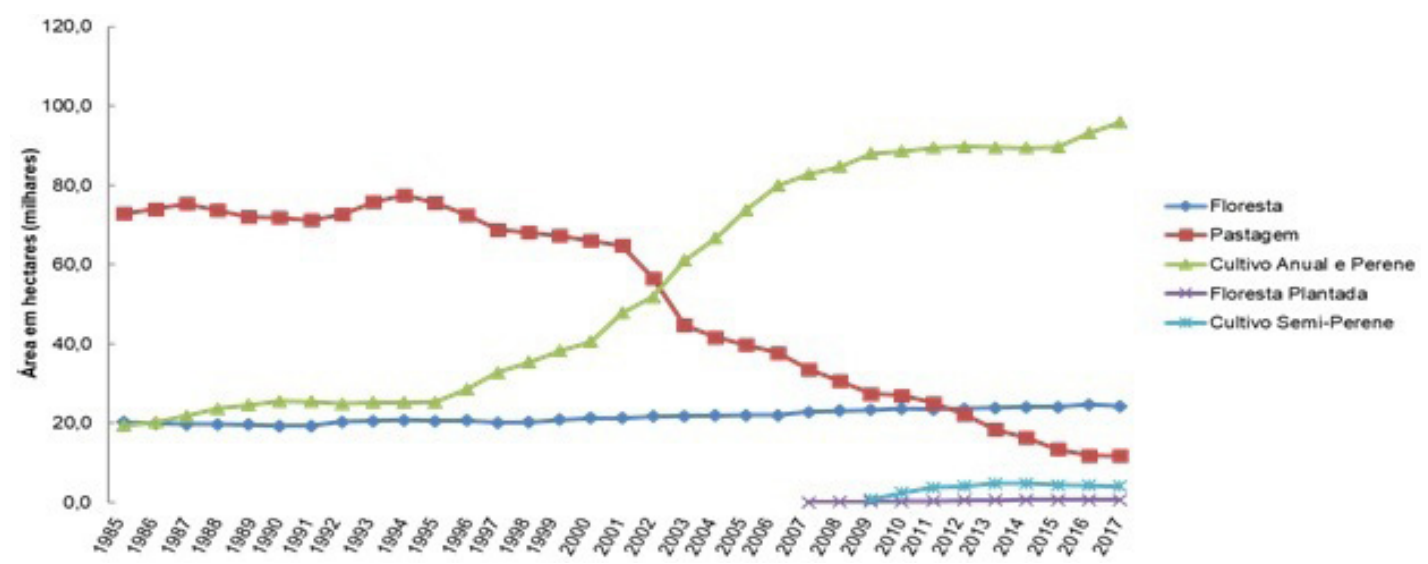

FIGURA 2 - Uso e ocupação do solo em hectares (ha) de 1987 a 2017 do município de Laguna Carapã. Fonte: Elaborada pelos autores, adaptado de https://mapbiomas.org/ (2021). ${ }^{1}$

${ }^{1} \mathrm{~A}$ transição de cultura do uso e ocupação do solo no município pode ser visualizada no vídeo disponível em https://www.youtube.com/ watch?v=OPD_0aXDBh4\&ab_channel=MarceloCanhota. 
5.2 As propriedades pecuárias no município de Laguna Carapã-MS

$\mathrm{Na}$ Tabela 1 são apresentados os dados referentes às 22 propriedades rurais, obtidos através do acesso ao acervo de instituições públicas de desenvolvimento rural e administração pública, oriundas de entrevistas a representações, autoridades e produtores locais. Dentre os dados obtidos existe a informação de que 12 propriedades $(54,5 \%)$ eram produtoras de leite, para subsistência, venda local, ou comercialização de laticínios (Figura 3A). Observou-se que $9(40,9 \%)$ eram produtores rurais de bovinos de corte. Apenas um pecuarista era produtor de bovinos de leite $\mathrm{e}$ de corte (sistema misto).

Dentre as propriedades avaliadas, $13(57,1 \%)$ apresentavam pouca ou baixa adoção de técnicas de manejo (apenas pastagem, sem práticas de correção da acidez do solo). Em alguns casos, no período de seca, utiliza-se suplementação alimentar como sal mineral e silagem. Essas foram classificadas por sistemas extensivos (Figura 3B). Um único produtor praticava manejo caracterizado pelo sistema intensivo, com maior nível de tecnificação com suplementação no cocho, piqueteamento (subdivisão) das pastagens, correção do solo e aplicação de insumos agrícolas visando qualidade nutricional da forrageira, pastejo rotacionado, suplementação alimentar com sal mineral, ração na época de estiagem ou inverno (junho a setembro) e uso de silagem.

Das propriedades avaliadas, 8 produtores $(38,1 \%)$ possuíam algum tipo de tecnificação, mas não para alta performance de produção, sendo classificados como semi -intensivo (Figura 3B). Quanto à principal renda, 7 (31,8\%) produtores tinham a bovinocultura como fonte primária (Figura 3C). A principal renda dos demais $(68,2 \%)$ foi relacionada com outras atividades, na maioria de cunho agrícola, como o arrendamento de áreas para cultivo canavieiro e produção de grãos (Figura 3C).

Também foi possível observar que as maiores taxas de lotação ( animal ha ${ }^{-1}$ ) foram identificadas em produtores de gado de leite (Tabela 1), o que evidenciou que esses produtores possuem mais animais por área comparados com os produtores de gado de corte, provavelmente por possuírem um sistema de manejo mais tecnificado.

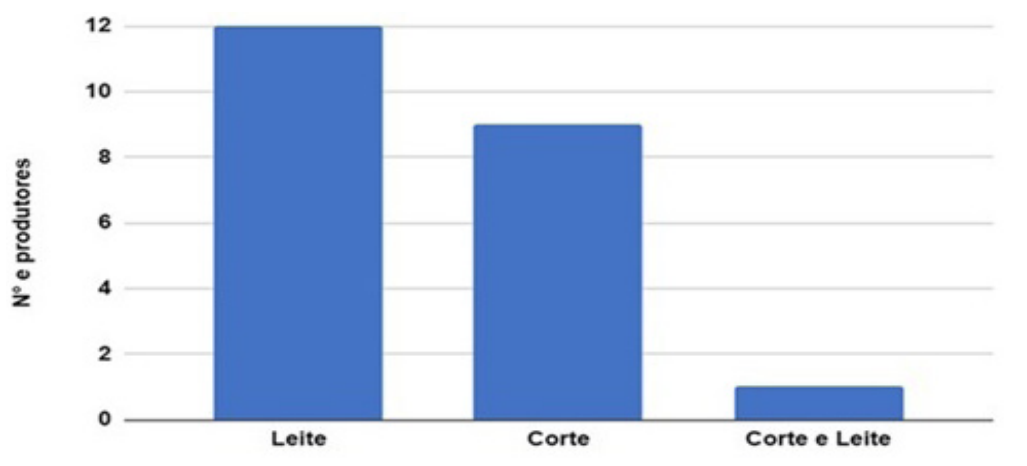

A

B
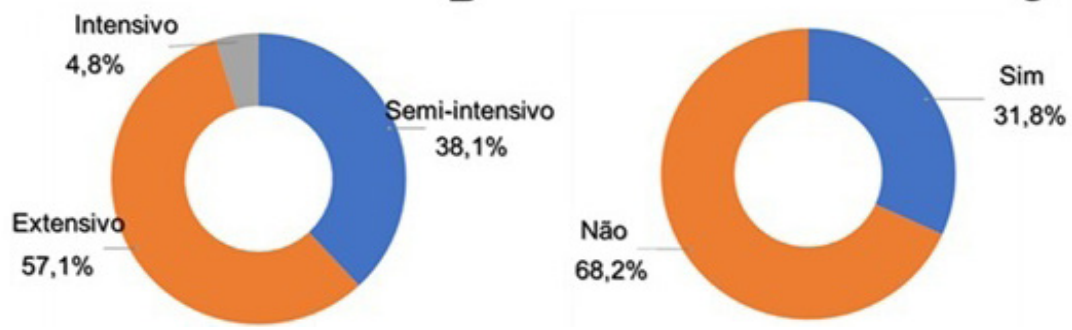

FIGURA 3 - A) Número de produtores de bovinos de leite e corte analisados no município de Laguna Carapã. B) Característica da produção pecuária quanto ao aspecto de manejo. C) Porcentagem de produtores que têm a produção de bovinos a pasto como sua principal renda. Ano: 2019.

Fonte: Elaborada pelos autores (2021).

Organizações Rurais \& Agroindustriais, Lavras, v. 23, e1789, 2021 
5.3 Séries históricas das propriedades pecuárias e rebanhos bovinos de Laguna Carapã-MS

A transição da atividade agropecuária, antes marcada pela bovinocultura extensiva com atual predominância de produção de grãos, cereais e energéticos, foi demonstrada na Figura 2. Nessa transição, observou-se a diminuição ordenhadas (Figura 4B) e da área de pastagens (Figura 4C) nas duas últimas décadas. Em 1997, havia cerca de 150 mil cabeças de gado no município. Em 2019, o número de cabeças foi menor que 30 mil. Assim, em 22 anos, o efetivo de rebanho diminuiu em 75\% (Figura 4A).

As vacas ordenhadas no município passaram de quase 2 mil cabeças em 1997 para aproximadamente 600 cabeças em 2018. Comparando séries históricas das áreas de pastagem no município (Figura 2) com o efetivo de rebanho (Figura 4C), foi possível estimar as taxas de lotação em série histórica no município (Figura 4D). Em 1997, a taxa de lotação foi de 1,9 animais ha-1, observando-se aumento subsequente. Em 2015, 2016 e 2017 a taxa de lotação foi de 4,1; 3,37 e 3,56 animais ha-1, respectivamente. Dentro do intervalo de tempo analisado, a correlação entre efetivo de rebanho e vacas ordenhadas foi $0,67(\mathrm{p}<0,001)$; entre efetivo de rebanho e área de pastagem foi $0,95(p<0,001)$; entre efetivo de rebanho e taxa de lotação foi $-0,67(p<0,001)$; entre vacas ordenhadas e área do efetivo de rebanho (Figura 4A), diminuição das vacas

de pastagem foi $0,65(p<0,001)$, e entre vacas ordenhadas e taxa de lotação foi $-0,63(\mathrm{p}<0,001)$.

\subsection{Análise visual da cobertura vegetal}

As visitas in loco aconteceram em cinco propriedades rurais, com vistas a estimativas do grau de degradação das pastagens. Uma propriedade era de produção de leite (propriedade O, Tabela 1), duas de corte (propriedades K e $\mathrm{B}$, Tabela 1), e outra propriedade era de gado de corte e de leite, simultaneamente, (propriedade I, Tabela 1). A quinta propriedade (propriedade T, Tabela 1) era caracterizada por pastagem arrendada, destinada à manutenção de vacas Girolanda secas, ou seja, vacas em período de gestação.

A $1^{\circ}$ propriedade visitada (Figura $5 \mathrm{~A}$; propriedade $\mathrm{T}$, Tabela 1), era constituída por aproximadamente 30 ha e 30 bovinos, sendo formada por $80 \%$ de reserva natural e $20 \%$ de pastagens do gênero Brachiaria sp. De acordo com o histórico, não foram realizadas correções e adubações no solo ao longo dos anos de uso. Notou-se a presença de cupinzeiros e exposição do solo de forma aleatória, sendo a pastagem classificada em nível 2 (moderadamente degradada). A $2^{\circ}$ propriedade (Figura 5B; propriedade K, Tabela 1), possuía 750 ha sob Brachiaria sp., e era pastejada por 1.059 bovinos da raça Gir e Nelore. Foi possível observar degradação com grande exposição do solo, além da formação de sulcos formados pelo escoamento superficial das águas das chuvas, bastante profundos $( \pm 0,50 \mathrm{~m})$, da presença de cupinzeiros e da baixa estatura da Brachiaria sp. no nível 4 (extremamente degradada).

A
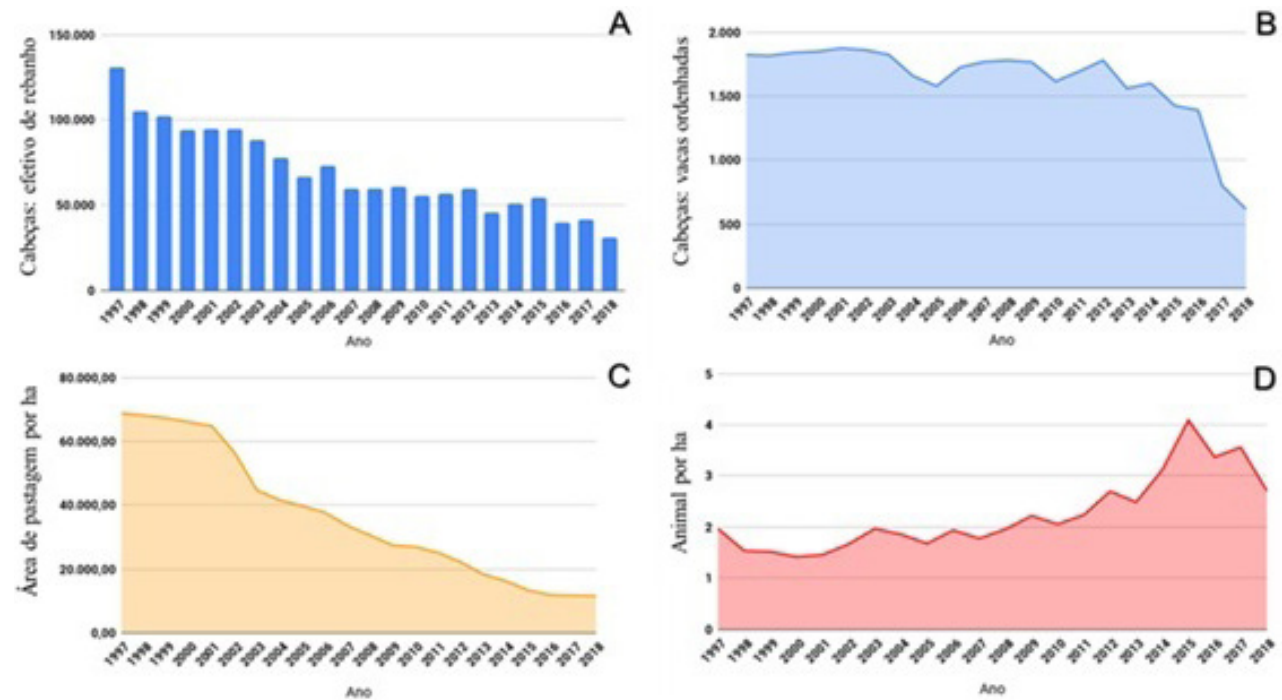

FIGURA 4 - Série história do efetivo de rebanho. A) Número de animais B) Vacas ordenhadas C) Área de pastagens por hectare D) Taxa de lotação animal por hectare no intervalo de: 1997 a 2018.

Fonte: Elaborada pelos autores (2021). 


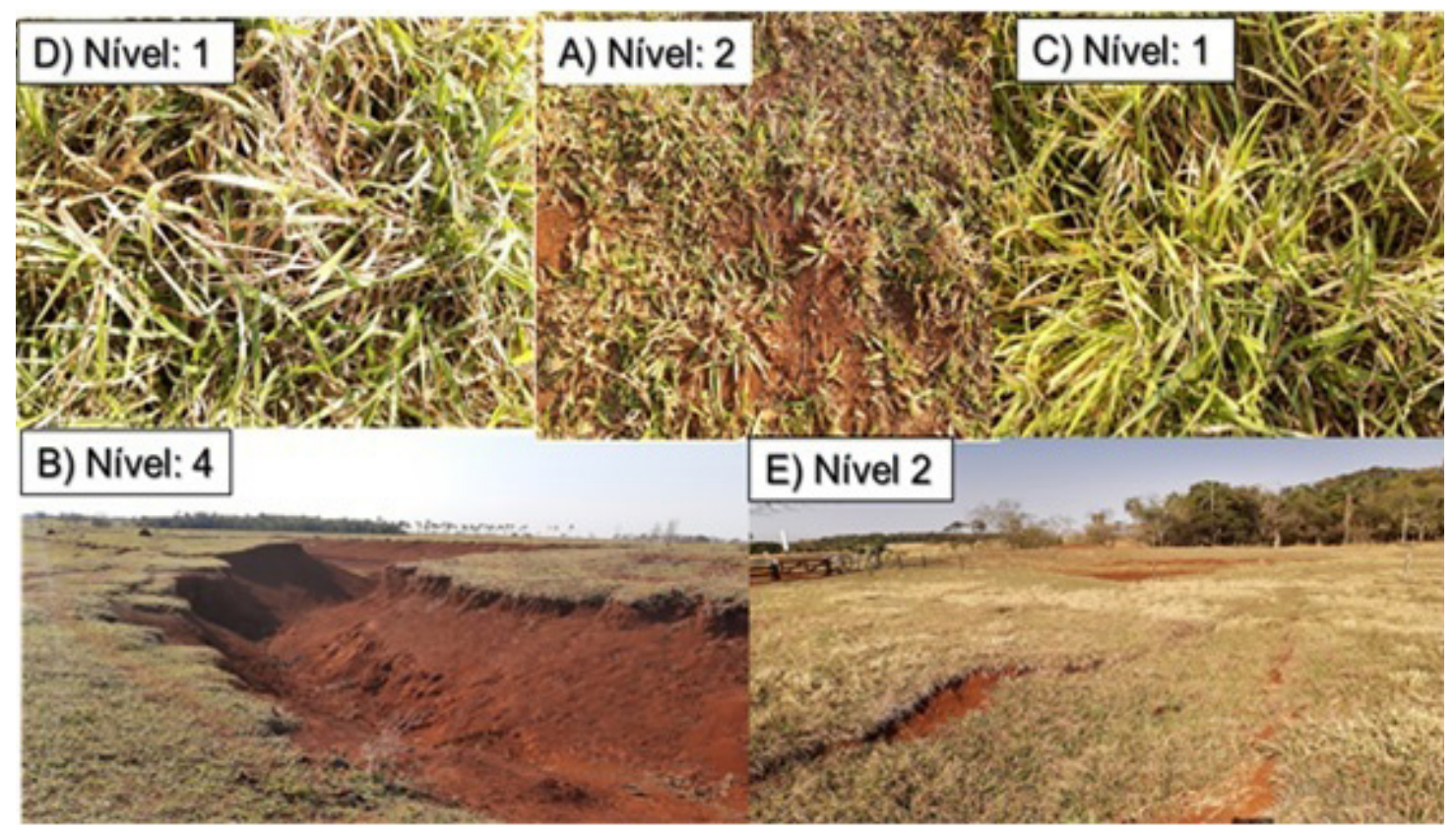

FIGURA 5 - Classificação de pastagens em 5 propriedades visitadas in loco no município de Laguna Carapã, segundo método de análise visual proposto por Dias-Filho (2017): 1= pastagem levemente degradada; $2=$ moderadamente degradada; $3=$ degradação forte; $4=$ degradação muito forte Fonte: Elaboradas pelos autores

A $3^{\circ}$ propriedade (Figura $5 \mathrm{C}$; propriedade $\mathrm{O}$, Tabela 1), possuía 26 ha próprios e 18 ha arrendados, apresentando 50 bovinos leiteiros Girolanda, instalações para ordenha eletrônica e resfriador. As pastagens eram formadas por Brachiaria sp. que era adubada todo ano com NPK (Nitrogênio, Fosforo e Potássio), e piqueteada para o manejo dos animais e da pastagem. Na estação das secas, os animais recebiam complementação alimentar por meio do sal mineral e ensilagem de milho. Não foi observada a presença de cupinzeiros, sendo a exposição do solo baixa, com apenas alguns, apenas alguns fragmentos de solo expostos de forma aleatória. Foi classificada no nível 1 (levemente degradada). A $4^{\circ}$ propriedade (Figura 5D; propriedade B, Tabela 1), era constituída de 350 ha de área de pastagens com aproximadamente 900 bovinos das raças Nelore e Red Angus. O manejo era realizado em piquetes. A pastagem era corrigida e adubada anualmente e os animais recebiam sal mineral. Apresentou boa qualidade visual e poucos locais com solo exposto, sendo classificada em nível 1 de degradação.

$\mathrm{A} 5^{\mathrm{a}}$ propriedade (Figura 5E; propriedade I, Tabela 1), possuía 303 ha com 400 bovinos das raças Holandês, Nelore e Angus. A principal atividade era comercialização do gado de corte e a produção de leite como atividade secundária, que era vendido in natura no município. Os pastos eram adubados, separados por piquetes, e visualmente possuíam média qualidade. Estes ainda apresentavam manchas de solo expostos de maneira aleatória, caracterizando degradação moderada (nível 2 de degradação).

\section{5 Índice de vegetação por diferença normalizada}

Os valores de NDVI no período de 2000-2019 das 22 áreas (Tabela 2) avaliadas permitiram verificar que as áreas sob pastagem foram similares entre si, com a média variando de 0,52 a 0,66 . Verificou-se, ainda, dados dispersivos com médio desvio padrão $\sim 0,15$, o que pode estar relacionado a alterações de uso do solo em vários momentos no intervalo de tempo avaliado.

Ao avaliar as áreas de acordo com os maiores valores de NDVI, sendo 6 delas sob produção de bovinos de corte e 6 sob bovinos de leite (Figura 6A e 6B), foi possível observar uma pequena variação. Essa diferença demonstra que aquelas que produzem gado de leite possuem uma leve superioridade de valores de NDVI, em relação às áreas de produção de gado de corte. Ou seja, possivelmente apresentam melhor qualidade das pastagens e menor degradação, como observado na análise in loco a campo. 


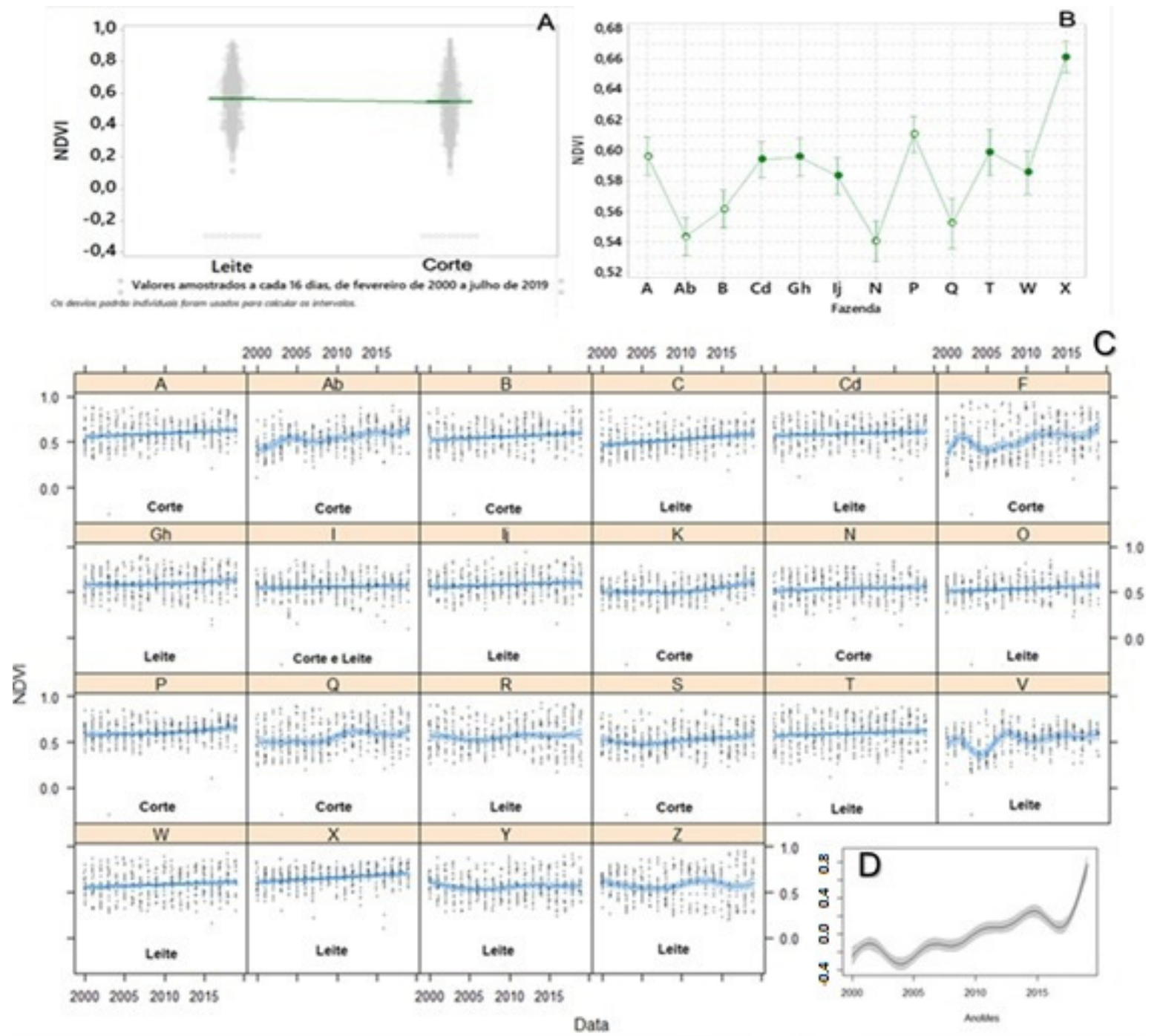

FIGURA 6 - Valores médios de NDVI global. A) seis maiores médias de produção de gado de corte e leite; B) distribuição dos valores de NDVI entre 12 propriedades no município de laguna Carapã, gado de corte (A, Ab, B, N, P, Q) e leite (Cd, Gh, Ij, T, W, X). As barras indicam o intervalo de confiança ( $\mathrm{p}<0,05)$; $\mathrm{C}$ ) Dispersão dos dados de NDVI no período de 2000 a 2019, das fazendas avaliadas no município de Laguna Carapã. A cor azul representa o intervalo de confiança, com $95 \%$ de probabilidade; D) Representação de todas as fazendas analisadas simultaneamente Fonte: Elaborada pelos autores (2021)

Também foi possível observar que a propriedade "X" com a maior média $(0,66)$ de NDVI (Tabela 2) trabalhava com gado leiteiro em sistema intensivo, com a maior taxa de lotação observada neste estudo (Tabela 1). Já a propriedade "K" com a menor média $(0,52)$ de NDVI (Tabela 2) era de gado de corte, com sistema extensivo e uma das menores taxas de lotação (Tabela 1), além de ter sido uma das cinco propriedades visitadas in loco, a qual foi classificada com o maior nível de degradação (Figura 5B). Isso revela que, de maneira geral, o NDVI é um bom indicador de qualidade de pastagem e manejo, podendo ser comparado e utilizado com outros dados e indicadores.

Analisando a dispersão de NDVI nas diferentes fazendas, a partir de séries históricas, foi possível notar que existem dois grupos possíveis de classificação das 
propriedades. As tortuosas (Figura $6 \mathrm{C}$, propriedades: $\mathrm{Ab}$, F, K, Q, R, S, V, Y e Z) possuem maior variabilidade de NDVI. Possivelmente essas áreas sofreram modificação de manejo e produção ao longo do tempo. Já as propriedades que apresentam um padrão mais linear de NDVI (Figura 6D, propriedades: A, B, C, Cd, Gh, I, Ij, N, O, P, $\mathrm{T}, \mathrm{W}$ e $\mathrm{X}$ ) possuem menor variabilidade ao longo da série temporal, sugerindo que não houve mudança de atividade no período analisado, apenas pastagens para alimentação animal. Analisando em conjunto as 22 áreas (Figura 6D) fica visível que ao longo dos 19 anos houve um aumento discreto do índice de vegetação. Assim, é possível inferir que, de maneira geral, houve um manejo diferenciado o qual provavelmente resultou em uma maior variabilidade de biomassa vegetal na série temporal analisada e no manejo, ao longo do tempo.

A tendência de transição de pastagens para sistemas de produção de grãos, sejam eles com a integração ou não, tem sido observada em muitas regiões e em todos os estados do Centro-Oeste, a exemplo do que ocorreu em Laguna Carapã, município de alta aptidão agropecuária. A expansão significativa da agricultura, acompanhada da retração de pastagens, pode ser consequência da consolidação de políticas de desenvolvimento de financiamento agrícola nessas regiões, como o Programa de Fortalecimento da Agricultura Familiar (Pronaf), o Programa Nacional de Crédito Fundiário (PNCF), entre outros. Ainda, o crescimento na produção de grãos foi, provavelmente, impulsionado pelo acesso facilitado aos insumos e à existência de uma nova cultura de produção de vazão (Parente et al., 2019). Entretanto, um dos principais fatores do aumento na produção de grãos tem sido a venda de produção primária ao mercado externo, ou seja, a exportação de commodities, especialmente a soja, além de viabilidade econômica no uso de fertilizantes (ZEE-MS, 2015; Mota Junior et al., 2020; Ogino et al., 2021).

O crescimento da produção de soja na região se viabilizou devido a fatores como a topografia plana; estabilidade dos níveis pluviométricos; disponibilidade de terras, que após a redução da acidez através da calagem se tornaram mais produtivas; além da migração de produtores do sul do Brasil, que já possuíam experiência com a cultura da soja (Campos \& Paula, 2002). É possível mencionar que essa mudança abrupta de uso do solo resulta de uma pressão de mercado, de uma mudança na maneira de pensar na agropecuária, e de uma forma de buscar novas alternativas de produção que levem o produtor a produzir cada vez mais e ao mesmo tempo, de forma mais sustentável (Zolin et al., 2021). Esse contexto também deve ser pensado por meio de uma história rural que leve em conta a agricultura convencional e a transição para um modelo sustentável, uma vez que os impactos da "sojização" da agricultura têm trazido consequências significativas aos ecossistemas nos quais ela se insere (Klanovicz \& Mores, 2017).

Ao investigar características sobre as propriedades pecuárias com acesso a informações oriundas de entidades governamentais e entrevistas (in loco, ou não), permitiuse compreender a situação da bovinocultura praticada no município. Sabe-se que a criação extensiva é praticada, muitas vezes, sem manejo adequado das pastagens, sendo que, no estado sul-mato-grossense, essa situação tem sido associada à degradação do solo e do meio ambiente (Borlachenco \& Barbosa, 2017). Isso poderia ser diferente se os produtores compreendessem que o uso de pastagens mais produtivas e de melhor qualidade, em conjunto com um manejo mais adequado para sua realidade, poderia alavancar os resultados econômicos e ambientais em relação ao cenário de manejo tradicional (Silva et al., 2017; Jank et al., 2014).

Ao analisar as séries históricas do efetivo de rebanho, vacas ordenhadas e taxa de lotação (Figura 4A, 4B e 4D), reiterou-se a transição de cultura constatada mediante dados de uso e ocupação de solo (Figura 2). Isso possibilitou constatar diminuição de quantidade de rebanho, produção de leite e pastagens, concomitante com o aumento na produção de culturas anuais e perenes (Dias-Filho, 2014). O aumento gradativo das taxas de lotação, indicador de quantidade de animais por área de pastagens, pode estar relacionado com a maior tecnificação das propriedades, investimento em insumos, e melhorias no manejo de pasto e rebanho.

Contudo, pode indicar, também, riscos no status das pastagens em se tratando do uso e conservação dos recursos forrageiros (superpastejo), que pode comprometer a produtividade da pastagem, com consequência nos índices de produção zootécnica e degradação do solo (Paulino \& Teixeira, 2010). O aumento das taxas de lotação (animal por hectare) foi acompanhado da diminuição do efetivo de rebanho e vacas ordenhadas, observado mediante estimativas de correlações negativas e significativas. Isso pode ser reflexo de pressões do mercado por produção agrícola, o que faz com que os bovinos sejam agrupados em menores áreas de pastagem, enquanto outras produções crescem, como a de grãos, cereais e energéticos.

A densidade de forrageiras, a frequência de pragas invasoras e as áreas ausentes de cobertura vegetal são 
frequentemente os sinais mais visíveis de degradação de pastagens. Contudo, estimar essas variáveis com análises visuais (in loco) é complexo. Os sinais de degradação das pastagens nem sempre são visíveis, dificultando sua detecção precoce (Valle Júnior et al., 2019). A avaliação das pastagens auxiliou substancialmente a pesquisa no município, embora a amostragem tenha limitado uma abordagem estatística mais robusta para a identificação de estereótipos, grupos ou a classificação de fazendas conforme a semelhança na prática da bovinocultura. Em pesquisas subsequentes, recomenda-se testar esses estereótipos ou tendências e entender melhor a degradação das pastagens. Isso só será possível com um mapeamento de maior número de propriedades (amostras) ao longo do município, ou mesmo do estado.

As visitas in loco (Figura 5), analisadas conjuntamente, revelaram notória variação nas características que habitualmente são utilizadas para definir níveis de tecnificação, investimento, estilos ou práticas na bovinocultura. A pastagem em pior condição não esteve atrelada às raças europeias, às fazendas de leite, nem às fazendas que praticam lavoura e criação de gado concomitantemente (culturas não consorciadas). As melhores pastagens foram observadas em fazendas de leite, com presença de lavoura (não consorciado com produção de gado, embora realizada na mesma fazenda). Esses achados de pesquisa motivam e estimulam a discussão sobre desenvolvimento sustentável da bovinocultura e do agronegócio local. Sensibilizam, sobretudo, para o fato de que as pastagens remanescentes estão em posse de pecuaristas que variam seu modus operandis na bovinocultura extensiva, possivelmente resultado de fatores adversos que enfrentam, externos à propriedade, e que repercutem no manejo praticado. Esse assunto tem relação, também, com discussões sobre a capacidade de sequestro de carbono atmosférico (Chaplot et al., 2016), biomassa vegetal (Fayiah et al., 2019), microbiota do solo (Ikoyi et al., 2018), e conservação dos agroecossistemas (Rana et al., 2018), entre outras temáticas relacionadas à sustentabilidade da atividade agropecuária.

Como as médias globais de NDVI tiveram uma variação entre 0,52 e 0,66 (Tabela 2), foi possível notar que essa faixa de valor ficou dentro do padrão de variação do índice que é de 0,2 a 0,8 (Karimi et al., 2016). Também foram constatados dados dispersivos com alto desvio padrão da média $\sim 0,15$ (Tabela 2), isso pode ter ocorrido devido a valores abaixo de zero, que podem indicar outro espectro luminoso que não coincide com o espectro vegetal, o qual pode estar relacionado com o solo exposto que apresenta baixos valores, normalmente negativos devido a degradação das pastagens, ou mesmo o intervalo de transição de cultura no solo (Demarchi et al., 2011). O contínuo empobrecimento dos solos das áreas de pastagens pode levar a um processo de degradação em que há substituição de espécies introduzidas (Brachiaria sp., por exemplo) por espécies menos exigentes em fertilidade do solo e manejo do pastejo, como a grama mato grosso (Paspalum notatum) e até mesmo barba de bode (Aristida longiseta), numa etapa mais avançada de degradação (Andrade et al., 2017).

De maneira geral os resultados do NDVI mostraram que existe uma variação entre produtores de gado de corte e leite analisados, tendenciando uma sutil maior qualidade de pastagens (maior índice de vegetação) (Aguiar et al., 2017) nas propriedades de gado leiteiro, comparado com as propriedades de gado de corte (Tabela 2 , figura 6A e 6B). Como observado in loco, os produtores leiteiros provavelmente investiram mais nas pastagens visando o aumento da produção de leite por animal, ou seja, a renda principal. Outro fator importante foi a dimensão de algumas propriedades, como de produtores leiteiros (menor que 200 ha), que facilita o manejo das pastagens (adubações e lotação animal) (Vilela et al., 2020). Isso também foi possível de ser notado devido ao NDVI ser um dos índices mais aceitos para analisar a cobertura vegetal e as mudanças do uso do solo (Mota Junior et al., 2020).

\subsection{Descrição socioeconômica do município de Laguna Carapã-MS}

Com os dados do IBGE Cidade, examinou-se que, em 2010, o PIB per capita do município de Laguna Carapã foi classificado em $202^{\circ}$, dentre os 5570 municípios do Brasil (IBGE, 2019c). O PIB per capita foi classificado em $12^{\circ}$ dentre os 79 municípios registrados no estado de MS. Quanto ao índice de desenvolvimento humano do município (IDHM), a posição de Laguna Carapã melhorou no ranqueamento dos municípios do país. Com base na escala do IBGE, o IDHM era classificado como muito baixo em $1990\left(3071^{\circ}\right.$ no ranqueamento nacional), baixo em $2000\left(2742^{\circ}\right)$, e médio em $2010\left(2621^{\circ}\right)$. A melhoria do IDHM foi averiguada com melhorias na renda, longevidade da população, e aspectos ligados à educação (Figura 7). 
1

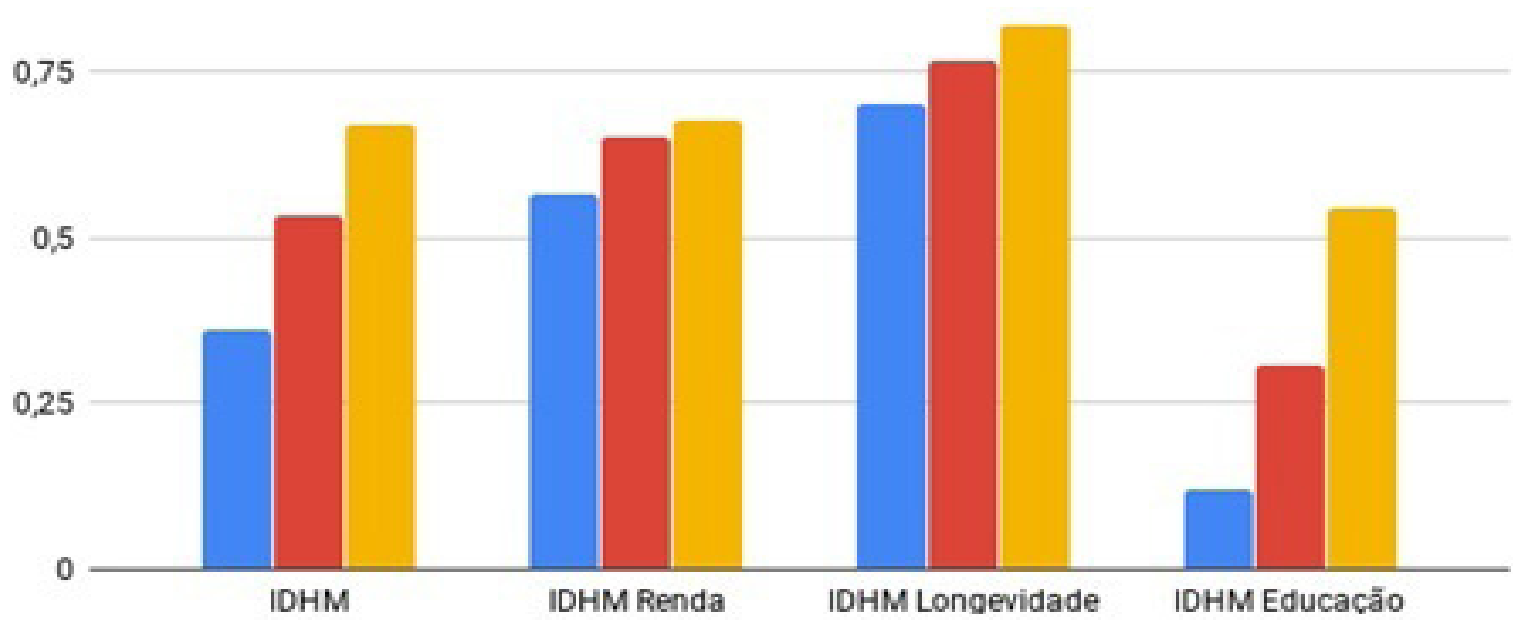

FIGURA 7 - Série história do índice de desenvolvimento humano municipal (IDHM) de Laguna Carapã, no período de 1991, 2000 e 2010.

Fonte: Elaborada pelos autores (2021).

\section{CONCLUSÕES}

O uso e ocupação do solo na região de Laguna Carapã mudou substancialmente nas últimas décadas. A transição foi marcante, sendo que as pastagens utilizadas para a produção de gado podem ser consideradas remanescentes. Elas possuem níveis de tecnificação que variam de moderado a nulo.

Quanto aos pecuaristas que continuaram com a produção de gado a pasto, as atividades que concorreram pelo uso da terra (milho, soja, trigo e cana-de-açúcar) provavelmente os estimularam a realizar mais investimentos na conservação e produtividade das pastagens.

A transição no uso e ocupação do solo foi acompanhada de melhorias nos indicadores zootécnicos, de desenvolvimento humano e desenvolvimento socioeconômico, o que sugere maior alinhamento com os objetivos e metas de desenvolvimento sustentável.

De modo geral, as pastagens remanescentes em fazendas produtoras de gado de leite apresentaram melhor aspecto (menor nível de degradação) comparado a fazendas de gado de corte. Isso foi observado nas visitas in loco, bem como nos dados concedidos por órgãos públicos e detectados pela variação do NDVI, o que revela uma tendência municipal de uso e ocupação do solo.
Seria oportuno encorajar e consolidar o manejo sustentável das pastagens para preservar os recursos naturais, impulsionar a produtividade (tempo de engorda e produção leiteira), e reduzir as emissões de gases de efeito estufa pelo sequestro de carbono promovido por gramíneas bem manejadas.

\section{REFERÊNCIAS}

Aguiar, D. A., Mello, M. P., Nogueira, S. F., Gonçalves, F. G., Adami, M., \& Rudorff, B. F. T. (2017). MODIS Time Series to Detect Anthropogenic Interventions and Degradation Processes in Tropical Pasture. Remote Sensing, 9(73), 1-20. https://doi.org/10.3390/rs9010073

Andrade, R. G., Bolfe, E. L., Victoria, D. C., \& Nogueira, S. F. (2017). Avaliação das condições de pastagens no Cerrado Brasileiro por meio de Geotecnologias. Revista Brasileira de Agropecuária Sustentável, 7(1). https://doi. org/10.21206/rbas.v7i1.376

Andrade, R. G., Rodrigues, C. A. G., Sanches, I. D., Torresan, F. E., \& Quartaroli, C. F. (2013). Uso de técnicas de sensoriamento remoto na detecção de processos de degradação de pastagens. Engenharia na agricultura, 21(3), 234-243. https://doi.org/10.13083/reveng.v21i3.368 
Barcellos, A. O., Ramos, A. K. B., Vilela, L., \& Martha Junior, G. B. (2008). Sustentabilidade da produção animal baseada em pastagens consorciadas e no emprego de leguminosas exclusivas, na forma de banco de proteína, nos trópicos brasileiros. Revista Brasileira de Zootecnia, 37, 51-67. https://doi.org/10.1590/S151635982008001300008

Bittman, S., Hunt, D. E., Kowalenko, C. G., Chantigny, M., Buckley, K., \& Bounaix, F. (2011). Removing solids improves response of grass to surface-banded dairy manure slurry: a multilayer study. Journal of Environmental Quality, 40(2), 393-401. https://doi. org/10.2134/jeq2010.0177

Borlachenco, N. G. C., \& Gonçalves, A. G. (2017). Expansão agrícola: elaboração de indicadores de sustentabilidade nas cadeias produtivas de Mato Grosso do Sul. Interações, 18(1), 119-128. https://doi. org/10.20435/1984-042X-2017-v.18-n.1(09)

Campos, A. C., \& Paula, N. M. (2002). A evolução da agropecuária brasileira nos anos 90. Indicadores Econômicos FEE, 29(4), 177-199. Recuperado de https:// revistas.planejamento.rs.gov.br/index.php/indicadores/ article/view/1344

Carvalho, W. T. V., Minighin, D. C., Gonçalves, L. C., Villanova, D. F. Q., Mauricio, R. M., \& Pereira, R. V. G. (2017). Pastagens degradadas e técnicas de recuperação: revisão. Pubvet, 11(10), 1036-1045. http://dx.doi. org/10.22256/pubvet.v11n10.1036-1045

Centro de Estudos Avançados em Economia Aplicada. (2021). PIB do agronegócio brasileiro, Dados de 1994 a 2019. Recuperado de https://www.cepea.esalq.usp.br/br/ pib-do-agronegocio-brasileiro.aspx

Chaplot, V., Dlamini, P., \& Chivenge, P. (2016). Potential of grassland rehabilitation through high density-short duration grazing to sequester atmospheric carbon. Geoderma, 271, 10-17. https://doi.org/10.1016/j. geoderma.2016.02.010

Cohn, A. S., Gil, J., Berger, T., Pellegrina, H., \& Toledo, C. (2016). Patterns and processes of pasture to crop conversion in Brazil: evidence from Mato Grosso State. Land Use Policy, 55, 108-120. https://doi.org/10.1016/j. landusepol.2016.03.005
Conceição, M. P. C., Nogueira, S. F., Grego, C. R., \& Manjolin, R. C. (2021). Avaliação temporal de sistemas pecuários usando o índice de vegetação NDVI derivado de imagens Landsat. Brazilian Journal of Animal and Evironmental Research, 4(1), 1451-1463. Recuperado de https://www. embrapa.br/busca-de-publicacoes/-/publicacao/1053862/ avaliacao-temporal-de-sistemas-pecuarios-usando-o-indicede-vegetacao-ndvi-derivado-de-imagens-landsat

Cunha, N. R. S., Lima, J. E., Gomes, M. F. M., \& Braga, M. J. (2008). A intensidade da exploração agropecuária como indicador da degradação ambiental na região dos Cerrados, Brasil. Revista de Economia e Sociologia Rural, 46(2), 291-323. https://doi.org/10.1590/S010320032008000200002

Cunha, J. E. B. L., Rufino, I. A. A., Silva, B. B., \& Chaves, I. B. (2012). Dinâmica da cobertura vegetal para a Bacia de São João do Rio do Peixe, PB, utilizando-se sensoriamento remoto. Revista Brasileira de Engenharia Agrícola e Ambiental, 16(5), 539-548. https://doi.org/10.1590/S141543662012000500010

Demarchi, J. C., Piroli, E. L., \& Zimback, C. R. L. (2011). Análise temporal do uso do solo e comparação entre os índices de vegetação NDVI e SAVI no município de Santa Cruz do Rio Pardo-SP, usando imagens Landsat-5. Raega - O Espaço Geográfico em Análise, 21. http://dx.doi. org/10.5380/raega.v21i0.17416

Dias-Filho, M. B. (2014). Diagnóstico das Pastagens no Brasil (Documentos 402). Embrapa Amazônia Oriental. Recuperado de http://ainfo.cnptia.embrapa.br/digital/ bitstream/item/102203/1/DOC-402.pdf

Dias-Filho, M. B. (2017). Degradação de Pastagens: o que é e como evitar. Embrapa Amazônia Oriental. Recuperado de http://www.infoteca.cnptia.embrapa.br/infoteca/handle/ doc/1070416

Empresa Brasileira de Pesquisa Agropecuária. (2019). SATVeg: Sistema de Análise Temporal da Vegetação. Recuperado de https://www.satveg.cnptia.embrapa.br

Faccini, A. C. T. M., \& Merêncio, V. S. (2019). Expansão do cultivo de cana-de-açúcar em Mato Grosso do Sul: a crise da usina São Fernando e implicações territoriais na região de Dourados-MS. Entre-Lugar, 10(19), 201-222. https://doi.org/10.30612/el.v10i19.9334 
Fayiah, M., Dong, S., Li, Y., Xu, Y., Gao, X., Li, S., Shen, H., Xiao, J., Yang, Y., \& Wessell, K. (2019). The relationships between plant diversity, plant cover, plant biomass and soil fertility vary with grassland type on Qinghai-Tibetan Plateau. Agriculture, Ecosystems and Environment, 286, 1-11. https://doi.org/10.1016/j.agee.2019.106659

Fonseca, E. L., Locatelli, M., \& Silva Filho, E. P. (2018). NDVI aplicado na detecção de degradação de pastagens cultivadas. Revista Franco-Brasileira de Geografia, 35(35), 1-17. https://doi.org/10.4000/confins. 13180

Food and Agriculture Organization of the United Nations. (2020). Land use in agriculture by the numbers. Recuperado de http:/www.fao.org/sustainability/news/ detail/en/c/1274219/

Guilherme, A. P., Mota, A. B. S., Mota, D. S., Machado, N. G., \& Biudes, M. S. (2016). Uso de Índice de Vegetação para caracterizar a mudança no uso do solo em CoariAM. Sociedade \& Natureza, 28(2), 301-310. Recuperado de http://www.seer.ufu.br/index.php/sociedadenatureza/ article/view/31538

Ikoyi, I., Fowler, A., \& Schmalenberger, A. (2018). Onetime phosphate fertilizer application to grassland columns modifies the soil microbiota and limits its role in ecosystem services. Science of the Total Environment, 630, 849-858. https://doi.org/10.1016/j.scitotenv.2018.02.263

Instituto Brasileiro de Geografia e Estatística. (2019c). IBGE Cidades, Brasil, Mato Grosso do Sul, Laguna Carapã. Recuperado de https://cidades.ibge.gov.br/brasil/ ms/laguna-carapa/panorama

Instituto Brasileiro de Geografia e Estatística. (2019a). IBGE cidades, Brasil, Mato Grosso do Sul, Laguna Carapã. Censo Agropecuário. Resultados definitivos 2017. Recuperado de https://cidades.ibge.gov.br/brasil/ ms/laguna-carapa/pesquisa/24/76693

Instituto Brasileiro de Geografia e Estatística. (2019b). Pesquisa Pecuária Municipal. Recuperado de https://sidra. ibge.gov.br/home/pnadcm

Jank, L., Barrios, S. C, Valle, C. B., Simeão, R. M., \& Alves, G. F. (2014). The value of improved pastures to Brazilian beef production. Crop and Pasture Science, 65(11), 1132-1137. https://doi.org/10.1071/CP13319
Karimi, N., Golian, S., \& Karimi, D. (2016). Monitoring deforestation in Iran, Jangal-Abr Forest using multitemporal satellite images and spectral mixture analysis method. Arabian Journal of Geosciences, 9(3), 1-16. https://doi.org/10.1007/s12517-015-2250-4

Klanovicz, J, \& Mores, L. (2017). A sojização da agricultura moderna no Paraná, Brasil: Uma questão de história ambiental. Fronteiras: Journal of Social Technological and Environmental Science, 6(2), 240-263. https://doi.org/10.21664/2238-8869.2017v6i2.p240-263

Liu, W. T. H. (2006). Aplicações de Sensoriamento Remoto ( $2^{\mathrm{a}}$ ed.). UNIDERP.

Macedo, M. C. M., Kichel, A. N. \& Zimmer, A. H. Degradação e alternativas de recuperação e renovação de pastagens. (2000). Comunicado Técnico, Embrapa Gado de Corte, 62. Recuperado de https:/www.embrapa.br/ busca-de-publicacoes/-/publicacao/324215/degradacaoe-alternativas-de-recuperacao-e-renovacao-de-pastagens

Projeto Mapbiomas v. 6. (2019). Recuperado de http:// mapbiomas.org/

Mota Junior, E. R., Trentin, C. B., Silva, I. S., Queiroz, I. L. C., \& Trentin, A. B. (2020). Monitoramento da degradação da pastagem e a incorporação de atividades agrícolas na microrregião do médio Araguaia-MT. Geoaraguaia, 10(2), 160-174. Recuperado de https://periodicoscientificos.ufmt. br/ojs/index.php/geo/article/view/10895

Ogino, C. M., Costa Junior, G., Popova, N. D., \& Martines Filho, J. G. (2021). Poder de compra, preço e consumo de fertilizantes minerais: uma análise para o centro-oeste brasileiro. Revista de Economia e Sociologia Rural. 59(1), 1-19. https://doi.org/10.1590/1806-9479.2021.220367

Organização das Nações Unidas Brasil. (2021). Objetivo de Desenvolvimento Sustentável, 15 Vida terrestre. Recuperado de https://brasil.un.org/pt-br/sdgs/15

Parente, L., Mesquita, V., Miziara, F., Baumann, L., \& Ferreira, L. (2019). Assessing the pasturelands and livestock dynamics in Brazil, from 1985 to 2017: A novel approach based on high spatial resolution imagery and Google Earth Engine cloud computing. Remote Sensing of Environment, 232, 1-11. https://doi.org/10.1016/j. rse.2019.111301 
Paulino, V. T., \& Teixeira, E. M. L. C. (2010). Sustentabilidade de pastagens: Manejo adequado como medida redutora da emissão de gases de efeito estufa. PUBVET, 4(24), 1-18. Recuperado de http://www.pubvet. com.br/artigo/2360/p-styletext-align-justify-aligncent erstrongsustentabilidade-de-pastagens-ndash-manejoadequado-como-medida-redutora-da-emissatildeo-de-gases-de-efeito-estufastrongp

Peron, A. J., \& Evangelista, A. R. (2004). Degradação de pastagens em regiões de cerrado. Ciência e Agrotecnologia, 28(3), 655-661. https://doi.org/10.1590/S141370542004000300023

Persson, Å., Eriksson, C., \& Lõhmus, M. (2018). Inverse associations between neighborhood socioeconomic factors and green structure in urban and suburban municipalities of Stockholm County. Landscape and Urban Planning, 179, 103-106. Recuperado de https:/www.cabdirect.org/ cabdirect/abstract/20193382406

Rana, K., Goyal, N., \& Sharma, G. P. (2018). Staging stewards of agro-ecosystems in the ecosystem services framework. Ecosystem Services, 33, 89-101. https://doi. org/10.1016/j.ecoser.2018.08.004

R Core Team (2020). R: A language and environment for statistical computing. $R$ Foundation for Statistical Computing. [Programa de computador]. Recuperado de https://www.R-project.org/

Reeves, M. C., \& Baggett, L. S. (2014). A remote sensing protocol for identifying rangelands with degraded productive capacity. Ecological Indicators, 43, 172-182. https://doi.org/10.1016/j.ecolind.2014.02.009

Resende, T. M., \& Rosolen, V. (2011). Degradação do solo pela conversão do cerrado em pastagem natural na Bacia do Ribeirão Bom Jardim (Triângulo Mineiro/MG). Ateliê Geográfico, 5(1), 118-134. https://doi.org/10.5216/ag.v5i1.13828

Salomão, P. E. A., Barbosa, L. C., \& Cordeiro, I. J. M. (2020). Pasture degraded areas recovery: a brief review. Research, Society and Development, 9(2), 1-18. https:// doi.org/10.33448/rsd-v9i2.2057

Secretaria de Estado de Meio Ambiente e Desenvolvimento Econômico. (2011). Região Sul-fronteira. Campo Grande, MS, 2011. Recuperado de http:/www.semade.ms.gov.br/ wpcontent/uploads/sites/20/2015/03/regiao_sul_fronteira_ caderno_geoambiental.pdf
Secretaria de Estado de Meio Ambiente, Desenvolvimento Econômico, Produção e Agricultura Familiar-SEMAGRO. (n.d.). Zoneamento Ecológico-Econômico de MS (ZEE$M S)$. SEMAGRO. Recuperado de https://www.semagro. ms.gov.br/zoneamento-ecologico-economico-de-ms-zee$\mathrm{ms} /$

Silva, M. C. Jesus, R. M., Carducci, C. E., \& Bahia, T. B. (2020). Mudanças na cobertura e uso da terra em Laguna Carapã: 1985-2017. [Arquivo de vídeo]. Recuperado de https://youtu.be/OPD_0aXDBh4

Silva, R. O., Barioni, L. G., Hall, J. A. J., Moretti, A. C., Veloso, R. F., Alexander, P., Crespolini, M., \& Moran, D. (2017). Sustainable intensification of Brazilian livestock production through optimized pasture restoration. Agricultural Systems, 153, 201-211. Recuperado de http:// www.bdpa.cnptia.embrapa.br/consulta/a?b=ad\&id=10654 $52 \&$ biblioteca $=$ vazio $\&$ busca $=1065452 \&$ qFacets $=106545$ $2 \&$ sort $=\&$ paginacao $=\mathrm{t} \&$ paginaAtual $=1$

Soares Filho, C. V., Monteiro, F. A., \& Corsi, M. Recuperação de pastagens degradadas de Brachiaria decumbens: variação sazonal de parâmetros bioquímicofisiológicos. (1992). Pasturas Tropicales, 14(2), 7-13. Recuperado de https://www.tropicalgrasslands.info/ public/journals/4/Elements/DOCUMENTS/1992-vol14rev1-2-3/Vol14_rev2_92_art3.pdf

Tomasella, J., Vieira, R. M. S. P., Barbosa, A. A., Rodriguez, D. A., Santana, M. O., \& Sestini, M. F. (2018). Desertification trends in the Northeast of Brazil over the period 2000-2016. International Journal of Applied Earth Observation and Geoinformation, 73, 197-206. https://doi. org/10.1016/j.jag.2018.06.012

United States Department of Agriculture. (2021). Market and trade data. Recuperado de https://www.fas.usda.gov/ index.php

Valle Júnior, R. F., Siqueira, H. E., Valera, C. A., Oliveira, C. F., Fernandes, L. F. S., Moura, J. P., \& Pacheco, F. A. L. (2019). Diagnosis of degraded pastures using an improved NDVI-based remote sensing approach: an application to the Environmental Protection Area of Uberaba River Basin (Minas Gerais, Brazil). Remote Sensing Applications: Society and Environment, 14, 20-33. Recuperado de https://www.sciencedirect.com/science/article/abs/pii/ S2352938518303409 
Vilela, L., Martha Junior, G. B., \& Sousa, D. M. G. (2020). Uso eficiente de corretivos e fertilizantes em pastagens. Revista Plantio Direto, 54-64. Recuperado de https:// ainfo.cnptia.embrapa.br/digital/bitstream/item/218158/1/ LVilela-et-al-RPD-Especial-Cerrado-2020.pdf

Young, N. E., Evangelista, P. H., Mengitsu, T., \& Leisz, S. (2020). Twenty-three years of forest cover change in protected areas under different governance strategies: A case study from Ethiopia's southern highlands. Land Use Policy, 91, 1-9. https://doi.org/10.1016/j.landusepol.2019.104426Get

Zimmer, A. H., Macedo, M. C. M., Kichel, A. N., \& Almeida, R. G. (2012). Degradação, recuperação e renovação de pastagens. Documentos, Embrapa Gado de Corte, 189. Recuperado de https://www.embrapa.br/ busca-de-publicacoes/-/publicacao/951322/degradacaorecuperacao-e-renovacao-de-pastagens

Zhumanova, M., Monning, C., Hergarten, C., Darr, D., \& Wrage-Monning, N. (2018). Assessment of vegetation degradation in mountainous pastures of the Western TienShan, Kyrgyzstan, using eMODIS NDVI. Ecological Indicators, 95, 527-543. Recuperado de https://www. cabdirect.org/cabdirect/abstract/20193194989

Zolin, C. A., Matos, E. S., Magalhaes, C. A. S., Paulino, J., Lal, R., Spera, S. T., \& Behling, M. (2021). Short-term effect of a crop-livestock-forestry system on soil, water and nutrient loss in the Cerrado Amazon ecotone. Acta Amazonica 51(2), 102-112. https://doi.org/10.1590/18094392202000391 